\title{
IMPLEMENTACIÓN DE LA PCR (REACCIÓN EN CADENA DE LA POLIMERASA) PARA EL DIAGNÓSTICO DE LA BRUCELOSIS DE BOVINOS EN EL ECUADOR
}

\author{
Orly Fernando Cevallos Falquez ${ }^{1}$, Emerick Motte ${ }^{2}$, Virna Cedeño ${ }^{2}$, Mercedes Susana Carranza Patiño ${ }^{1}$, \\ Hayron Fabricio Canchignia Martínez ${ }^{1}$ y Silvia Gicela Saucedo Aguiar ${ }^{1}$ \\ ${ }^{1}$ Universidad Técnica Estatal de Quevedo, Laboratorio de Biotecnología, Unidad de Investigación de Ciencia y \\ Tecnología. Quevedo, Los Ríos, Ecuador.Km.1.5 Via Sto.Domingo. orlycevallos@hotmail.com \\ ${ }^{2}$ Programa de Biotecnología, Universidad de Guayaquil. Guayaquil, Guayas, Ecuador
}

\begin{abstract}
RESUMEN
En el presente trabajo se implementó la técnica de PCR para la detección de Brucella abortus, en muestras de sangre, en comparación con la prueba Rosa de bengala. La amplificación del ADN se realizó utilizando tres oligonucleotidos homólogos correspondientes a la secuencia $16 \mathrm{ARNr}$ de Brucella abortus, dando una amplificación de 900 y $725 \mathrm{pb}$ respectivamente. Un total de 172 muestras de sangre fueron recolectadas de 4 hatos con prevalencia histórica de presencia de brucelosis. Resultaron 142 negativas con la prueba de serológia y 143 con PCR, 30 resultaron positivas con la prueba serológica Rosa de bengala y 29 salieron positivas con PCR. Todos los animales que salieron positivos con Rosa de bengala, 4 presentaban síntomas clínicos como son; abortos, terneros débiles, baja producción de carne y leche. Los otros 26 animales resultaron negativos con PCR y estos animales no presentaron los síntomas clínicos. De los 142 animales que dieron negativo con Rosa de bengala, 25 resultaron positivos con PCR. Los resultados muestran que la detección de los animales positivos mediante la PCR fue más especificas y sensibles que la prueba serológica de Rosa de bengala, por lo tanto es una herramienta muy útil en el diagnóstico de Brucella abortus .
\end{abstract}

Palabras claves: PCR, rosa de bengala, Brucella abortus, vacuna cepa 19 y brucelosis.

\begin{abstract}
In the present work I implement the technique of PCR for the detection of Brucella abortus, in blood samples, comparison with the Rose of bengal test. The amplification of the DNA was made using three oligonucleotidos homologous corresponding ones to the sequence $16 \mathrm{ARNr}$ de Brucella abortus, giving a 725 amplification of 900 and pb respectively. A total of 172 blood samples was collected of 4 cattle ranches with historical prevalence of brucelosis presence. Were 142 refusals with the test of serológia and 143 with PCR, 30 were positive with the Pink serológica test of Bengal and 29 left positive with PCR. All the animals that left positives with Rose Bengal, 4 presented clinical symptoms as they are; weak abortions, bull calves, low production of meat and milk. The other 26 animals were negative with PCR and these animals did not present/display the clinical symptoms. From the 142 animals that gave negative with Rose of Bengal, 25 were positive with PCR. The results show that the detection of the positive animals by means of the PCR was more you specify and sensible that the serológica test of Rose of Bengal, therefore is a very useful tool in the diagnosis of Brucella abortus.
\end{abstract}

Key words: PCR, rose of bengal, Brucella abortus, vaccine stock 19 and brucelosis.

\section{INTRODUCCIÓN}

Dentro de la comunidad científica la brucelosis, está catalogada como una de la zoonosis más importante del mundo, tanto por las pérdidas económicas que genera en la ganadería como por su impacto en la salud pública (Dajer et al., 1998). Esta enfermedad es causada por varias especies del género Brucella spp., B. abortus, B. melitensis, B. suis, B. neotomae, B. ovis, y $B$. canis, las cuales son aeróbicos no fermentadores que provocan infecciones intracelulares y que tienen

Recibido: Octubre, 2007. Aceptado: Diciembre: 2007.

Publicado como ARTíCULO en Ciencia y Tecnología 1: 31-36. 2008. una fuerte tendencia a establecer procesos crónicos (López et al., 1992). La enfermedad en el ganado bovino y otros animales, reservorios principales de las brucelas, se traduce generalmente en una orquiepididimitis en los machos y aborto en el último tercio de la gestación, mamitis, retención de placenta, nacimiento de terneros débiles y descenso en la producción de leche en las hembras. Su transmisión al humano puede ocurrir por contacto directo con animales infectados o en forma indirecta por ingestión de leche o productos lácteos contaminados, no sometidos a ningún proceso de conservación como la pasteurización o ebullición (Sutherland, 1980). 
Entre los países de Sudamérica, Brucella abortus presenta una mayor prevalencia de esta enfermedad, específicamente en ganado lechero, con valores que oscilan entre $0.1 \%$ y $20.3 \%$. Además se calcula que las pérdidas económicas causadas por la brucelosis bovina en las Américas ascienden a US\$ 270'000.000; esta estimación se basa en la pérdida de producción de crías (47\%), producción de leche (41\%) y costo de reposición (12\%) ICA (1999).

Ecuador, considerado como un país ganadero que posee tanto ganado lechero estabulado como rústico. En un reporte del Servicio Ecuatoriano de Sanidad Agropecuaria de abril del 2002, manifiesta que la brucelosis causada por Brucella abortus esta difundida en mayor o menor grado en todo el país, causando pérdidas que sobrepasan los US\$ $3^{\prime} 000.000$ anuales que corresponden al $18 \%$ de la población de ganado bovino que está afectada por esta enfermedad (SESA, 2002).

Aunque se han identificado todos los elementos para el control de la brucelosis en los humanos y en los animales, una de las principales limitantes para su total erradicación es la dificultad para lograr un buen diagnóstico, confiable y oportuno. El diagnóstico de brucelosis generalmente es realizado por métodos bacteriológicos o serológicos.

Los métodos de detección bacteriológicos suelen requerir días o semanas para lograr el crecimiento exitoso de las bacterias de Brucella spp. Por otra parte, las pruebas serológicas tradicionales presentan la desventaja de ser poco sensibles y/o específicas, pudiéndose tener falsos positivos causados por otros tipos de bacterias tales como: Yersinia enterocolitica, Vibrio cholerae, Salmonella, Escherichia coli. La causa de esta reactividad cruzada es por la gran similitud de los lipopolisacárido (LPS) presente en la superficie de estas bacterias. Mientras que resultados falsos negativos pueden ocurrir durante las primeras etapas de la enfermedad o en casos de infección focal (Al - Attas et al., 2000; Bustamante et al., 2000; Mitta, 1980).

Debido a su sensibilidad y especificidad para detectar cantidades mínimas y especificas de organismos tanto en fluidos corporales provenientes de animales en la primera etapa de infección, así como muestras de sangre contaminada, la técnica de amplificación de ácidos nucleicos por medio de la Reacción en Cadena de la Polimerasa (PCR) y sus variantes, resulta cada vez una mayor alternativa para diagnosticar enfermedades infecciosas causadas por microorganismo desagradables o de lento crecimiento, tales como los del género Brucella spp (Romero et al., 1996; Rijipens et al., 1996). Otra de la ventaja de esta técnica molecular es que permite un diagnóstico más rápido y eficaz en aproximadamente 6 horas (Cerba, 1998).

En base a lo anterior, en el presente trabajo se planteó como objetivo implementar la técnica de la PCR para el diagnóstico de la Brucella abortus en el Ecuador, en muestras de sangre seropositivas a brucelosis, en comparación con la prueba serológica Rosa de bengala.

Para la detección especifica de Brucella abortus en bovinos por la técnica de PCR, se emplearon iniciadores derivados de la secuencia $16 \mathrm{~S} \mathrm{ARNr}$ que fueron publicados en el EMBL-X13695 del GenBank.

\section{MATERIALES Y MÉTODOS}

\section{Recolección de muestras y pruebas serológicas}

Para la implementación de la técnica de la PCR, se seleccionaron 172 animales, de los cuales se extrajeron 5 $\mathrm{mL}$ de sangre, se le agrego anticoagulante, se la tomó en la parte posterior donde se encuentra la vena coccígea. La toma de muestra se la realizó en cuatros haciendas ganaderas ubicadas en los cantones de El Empalme y Pichincha (Prov. Guayas-Manabí, respectivamente).

\section{Extracción de ADN con el Protocolo de Lisis de Eritrocitos a Partir de Sangre Total de Bovino (Leal - Klevezas et al., 1995)}

Se tomaron $400 \mu \mathrm{L}$ de la muestra y se microcentrifugó a $7.000 \mathrm{rpm}$ por 3 minutos. El ADN fue resuspendido en $1 \mathrm{~mL}$ de solución de lisis de eritrocitos $\left(155 \mathrm{mM} \mathrm{NH}_{4} \mathrm{CL}, 10 \mathrm{mM} \mathrm{NaHCO}{ }_{3}, 100 \mathrm{Mm}\right.$ disodium EDTA pH 7.4). Se mezcló y se microcentrifugó a 7000 rpm por $3 \mathrm{~min}$. El tratamiento con solución de lisis de eritrocitos se repitió otra vez. El ADN templete se obtuvo a partir de los leucocitos como sigue: $400 \mu \mathrm{L}$ de solución de lisis ( $2 \%$ de Triton $\mathrm{x}-100,1 \%$ de SDS, $100 \mathrm{mM}$ de Nacl, $10 \mathrm{mM}$ Tris-HCl, pH 8) y $10 \mu \mathrm{L}$ de proteinasa $\mathrm{K}\left(10 \mathrm{mg} \mathrm{mL}^{-1}\right)$ se le añadió a las muestras. El contenido se mezcló con el uso del vortex y se incubó por $\left(40 \mathrm{~min}\right.$. a $\left.50{ }^{\circ} \mathrm{C}\right)$. Luego se añadió $400 \mathrm{uL}$ de fenol saturado (contenido de fenol líquido a $0.1 \%, 8$ hidroxiquinolina, saturado y estabilizado con $100 \mathrm{mM}$ Tris-Hcl (pH 8) y $0.2 \% 2$ mercaptoetanol, y se vortezó y a continuación se microcentrifugó a $13.000 \mathrm{rpm}$ por 5 min. La capa acuosa se transfirió a otro tubo y se le agregó un volumen igual de alcohol isoamil-cloroformo (24:1), el tubo se mezcló a fondo y se microcentrifugó a $10000 \mathrm{rpm}$ por $5 \mathrm{~min}$. La capa de arriba se transfirió a otro tubo y se le agregó $200 \mu \mathrm{L}$ de acetato de amonio $7.5 \mathrm{M}$ y se vortezó. Luego se colocó en hielo por 10 minutos, y después se microcentrifugó a 10,000 rpm por 5 min. y el contenido acuoso se transfirió a otro tubo. Dos volúmenes de etanol al $95 \%$ se añadió, se mezcló y el tubo fue almacenado a $-20^{\circ} \mathrm{C}$ por 30 minutos. 
Se recuperó el ADN por microcentrifugación a $10,000 \mathrm{rpm}$ por $5 \mathrm{~min}$. El ADN se lavo con etanol al 70\%, secado y resuspendido en $20 \mu \mathrm{L}$ de TE buffer ( $10 \mathrm{mM}$ trisHCL pH 8, y 1 mM Disodiun EDTA). La concentración del ADN se determinó por medición DOA260 y las extracciones se almacenaron $\mathrm{a}-20^{\circ} \mathrm{C}$ hasta su proceso de la PCR. Se incluyó siempre un control negativo de la extracción de ADN empleando agua destilada estéril en vez de sangre total y procesándola de la misma manera que las muestras de sangre total.

\section{Diseño de los oligonucleótidos sintéticos}

Para detectar la presencia del patógeno, se seleccionaron tres oligonucleótidos homólogos de la secuencia 16SARNr (Leal-Kleveza et al., 1995). Los iniciadores correspondieron a la secuencias F4 5'-TCGAGCGCCCGCAAGGGG-3'; R2 5'-AACCATAGTGTCTCCACTAA-3' y Ab15'GCGACGATCCATAGCTG-3' (Comercializado por GENERSA S. A.)

\section{Amplificación del ADN por medio de la PCR}

Se utilizó un volumen total de $50 \mu \mathrm{L}, 1 \mu \mathrm{L}$ de ADN para cada uno de las reacciones, $5 \mu \mathrm{L} \mathrm{10xBuffers,}$ $0.2 \mu \mathrm{L}$ de taq polimerasa $(5 \mathrm{U}), 4 \mu \mathrm{L}$ de dNTPs $(200$ $\mu \mathrm{L}$, de cada uno), $1 \mu \mathrm{L}$ de los oligonucleótidos (25 pmol de cada oligonucleótidos), $3 \mu \mathrm{L}$, de $\mathrm{MgCl}_{2}$ (3 $\mathrm{mM} \mathrm{MgCl}_{2}$ ), y $34.8 \mu \mathrm{L}$ de agua ultrapura estéril. Los controles negativos fueron, el contenidos del mix sin el ADN templete. La reacción fue programada en un termociclador (Pelkín -Elmer). Las condiciones de amplificación se basaron en un programa de $94{ }^{\circ} \mathrm{C}$ por cuatro minutos y, 40 ciclos de $94{ }^{\circ} \mathrm{C}$ por minuto, $56{ }^{\circ} \mathrm{C}$ por ochenta segundos y $72{ }^{\circ} \mathrm{C}$ por ochenta segundos y una extensión final de $72{ }^{\circ} \mathrm{C}$ por diez minutos. Para el juego de oligonucleótidos F4-R2. y Ab1.

\section{Electroforesis en gel de agarosa}

Los fragmentos amplificados fueron analizados mediante electroforesis en gel de agarosa al $2 \%$ en una solución de Buffer TAE (Tris -Base, Acido Acético, 0.5 M y EDTA pH 8) y se le agregó Bromuro de etidio $2 \mu \mathrm{L}$ $\mathrm{mL}^{-1}$. Para ello, $15 \mu \mathrm{L}$ de cada muestra se mezclaron con $3 \mu \mathrm{L}$ de solución tamponada de carga $(2.5 \mathrm{~mL}$ de azul de bromofenol al 1\%, $2.5 \mathrm{~g}$ de Ficoll, $1 \mathrm{~mL}$ de EDTA $0.5 \mathrm{M}$ al pH 8.0). La migración fue a $70 \mathrm{~V}$ por una hora. Los productos de amplificación se detectaron mediante visualización de las bandas bajo luz UV. Las imágenes se capturaron con una cámara Sony. Como marcador de peso molecular se empleó uno de 100 pb de ADN (Gilco BRL).

\section{RESULTADOS}

\section{Análisis Serológico y PCR}

Delas 172 muestras de sangre recolectadas en cuatro hacienda ganadera, del cantón El Empalme y Pichincha, $30(17.44 \%)$ resultaron positivas y $142(82.56 \%)$ resultaron negativas a la prueba Rosa de bengala y 29 (16.86\%) resultaron positivas y $143(83.14 \%)$ resultaron negativas a PCR (Cuadro 1). El protocolo de Extracción de ADN por Lisis propuesto por (Leal - Klevezas et al., 2000), fue más eficiente en cuanto a la extracción de ADN genómico, se obtuvo ADN de buena calidad en mayor cantidad, sin degradación, que migró en el gel de agarosa (Figura 1), en donde se observa que las 8 bandas pertenecientes a los ocho animales, presentan los dos tipos de ADN (genómico y mitocondrial). La cantidad de ADN extraídos se estimó entre $30 \mu \mathrm{g} \mathrm{mL} \mathrm{m}^{-1}$ entre las muestras $(2$ y 4$)$ mientras tanto que para las muestras $(1,3,5,6,7$ y 8) se estimó entre los $90 \mu \mathrm{g}$ $\mathrm{mL}^{-1}$. El rango de pureza para el primer grupo $(2 \mathrm{y} 4)$ fue estimado en $1.87 \mathrm{~nm}$ y para el segundo $(1,3,5,6,7 \mathrm{y}$ 8 ) entre $1.98 \mathrm{~nm}$. Se estimó este ADN competente para realizar las pruebas de PCR.

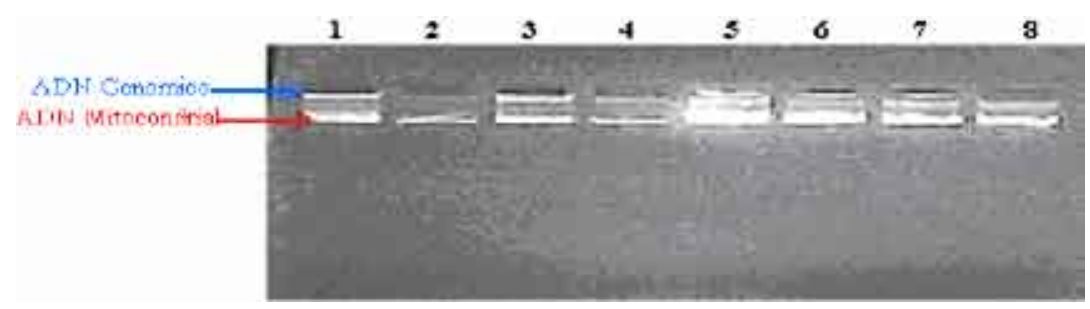

Figura 1. Resultados de la extracción de ADN genómico (Extracción de ADN con Lysis Buffer) de ochos muestras de sangre total de bovino en geles de agarosa teñidos con bromuro de etidio con el protocolo de Lisis 
Cuadro 1. Resultados de los estudios serológico, clínico y molecular para el diagnóstico de Brucella abortus de cuatro Haciendas en el Cantón El Empalme y Pichincha

\begin{tabular}{|c|c|c|c|c|c|c|c|}
\hline \multirow{2}{*}{ Hcda. } & \multirow{2}{*}{$\begin{array}{l}\text { Número de } \\
\text { animales } \\
\text { muestreado }\end{array}$} & \multicolumn{2}{|c|}{ RB } & \multicolumn{2}{|c|}{ PCR } & \multicolumn{2}{|c|}{ Clínico } \\
\hline & & - & + & - & + & - & + \\
\hline L.Intriago & 15 & 6 & 9 & 0 & 15 & 0 & 15 \\
\hline D.Aguirre & 10 & 4 & 6 & 0 & 10 & 0 & 10 \\
\hline R.Tuarez & 90 & 20 & 70 & 4 & 86 & 4 & 86 \\
\hline S.Fernandez & 57 & 0 & 57 & 25 & 32 & 25 & 32 \\
\hline Total & 172 & 30 & 142 & 29 & 143 & 29 & 143 \\
\hline
\end{tabular}

En las 15 muestras de sangre recolectadas en la hacienda del Dr. Linconl Intriago (Maria Isabel). Los animales no presentaron síntomas de esta enfermedad al realizar el análisis clínico. Con la prueba de Rosa de bengala, los resultados dieron 6 positivas equivalente al $40 \%$ y 9 negativas $60 \%$ respectivamente. Al analizar estas muestras con la técnica de PCR, todas las muestras dieron resultados negativos (Cuadro 1). En las 10 muestras de sangre recolectadas en la hacienda del Dr. David Aguirre (El Chonero), los animales no presentaron síntomas de esta enfermedad al realizar el análisis clínico. Con la prueba de Rosa de bengala los resultados dieron 4 positivas equivalente al $40 \%$ y 6 negativas $60 \%$ respectivamente. Para reconfirmar estos resultados se procedió al análisis por PCR con el juego de oligonucleótidos F4-R2, obteniendo resultados negativos para estas diez muestras excepto el control positivo.

En las 90 muestras de sangre recolectadas en la Hda. del Ing Ricardo Tuárez (Sta. Cecilia) dentro de esta población hubieron cuatro animales que presentaron síntomas de la enfermedad como es aborto, reducción de leche y, nacimientos de terneros débiles. Con la prueba de Rosa de bengala los resultados dieron 20 positivas equivalente al $22.2 \%$ y 70 negativas $77.8 \%$ respectivamente; Para reconfirmar estos resultados se procedió al análisis de veinte muestras seleccionadas aleatoriamente, para la PCR se utilizó el juego de oligonucleótidos F4-F5. Los resultados obtenidos en la figura 2, determinan que las bandas presentes en las líneas 2, 3, 4, y 5 determinan PCR positivos. Las líneas 6 y 7 negativos y, las líneas $\mathrm{C}+$ y $\mathrm{C}$ - son los controles respectivos, el total de las 16 muestras por ser negativas no se muestran (Figura 2).

En las 57 muestras de sangre recolectadas en la Hda. del Señor Salvador Fernández (Pacaritambo), los animales presentaron síntomas moderados de la enfermedad al realizar el análisis clínico con la prueba de Rosa de bengala, los resultados dieron negativos el $100 \%$. Para reconfirmar estos resultados se procedió al análisis de las 57 muestras, para la PCR se utilizó el juego de oligonucleótidos F4-R2. Los resultados obtenidos demostraron que del total de muestras (57), 25 salieron PCR positivos (todos los datos no presentados) lo que representa el $43.86 \%$. (Figura 2).

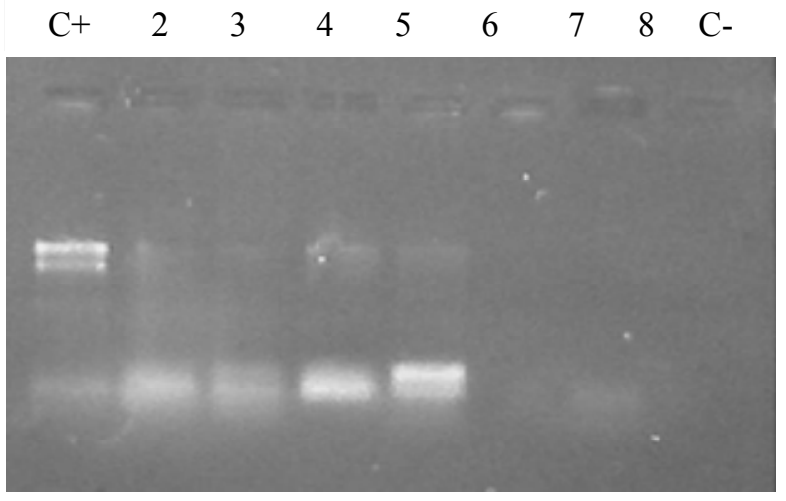

Figura 2. Resultados de la PCR con muestras de sangre de bovino con los oligonocleotidos F4 - R2

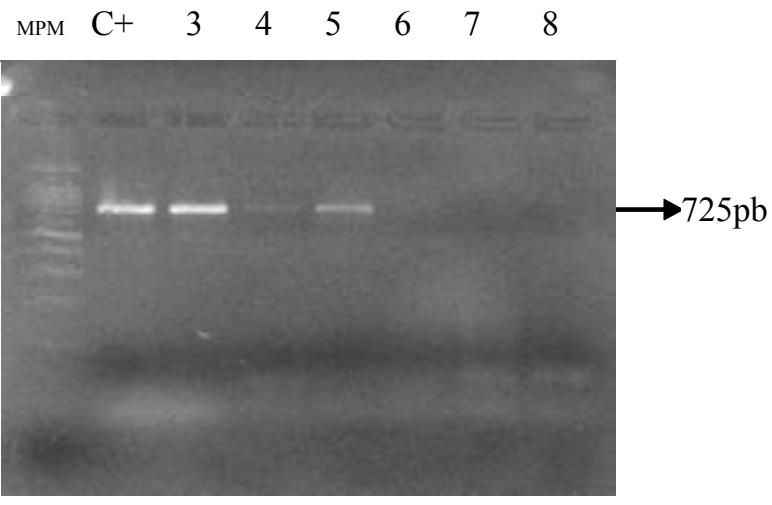

Figura 3. Resultados de la PCR con muestras de sangre de bovino con los oligonucleotidos AB1 - R2

Los resultados obtenidos en la Figura 2, muestran que las bandas presentes en las líneas 2, 3, 4, y 5 determinan PCR positivos. Las líneas 6 y 7 negativos $\mathrm{y}$, las líneas $\mathrm{C}+\mathrm{y} \mathrm{C}$ - son los controles respectivos, el total de las 16 muestras por ser negativas no se muestran. En la figura tres se muestran los resultados de amplificaciones de cinco muestras seleccionadas al azar negativas y positivas clínicamente. En la línea MPM (Marcador de Peso Molecular); Línea $2(\mathrm{C}+)$ control 
positivo; Línea 3, 4 y 5 muestras positivas y, en la Línea 6 y 7 muestras negativas, en la Línea 8 control negativo.

\section{DISCUSIÓN}

En el marco de la creación de nuevas herramientas que permitan efectivizar el diagnóstico de la Brucella spp. en animales y, la detección en el hombre por la relación zoonósica que presenta la bacteria. Además, en el ámbito ganadero las perdidas por eventos relacionados con la brucelosis en el Ecuador han llegado a constituir hasta un $43 \%$ de abortos en los hatos ganaderos. En la actualidad se vio una amplia necesidad de poder realizar este trabajo que fue dirigido al desarrollo de una PCR, logrando así el primer estudio por técnicas moleculares en el Ecuador.

Varios autores han reportado técnicas para el diagnóstico molecular mediante PCR del agente causal de la brucelosis y señalan su alta especificidad y sensibilidad. En esta investigación se utilizaron los oligonucleótidos que fueron reportados por (Romero et al., 1995a) derivados de la secuencia 16S ARNr que fueron publicados en el EMBL-X13695 del GenBank. Los oligonucleótidos F4-R2 y Ab1-R2 mencionado en (materiales y métodos) y que amplifican dos fragmentos de 900 pb y 725 pb, específicos del genoma de Brucella que permite la identificación y la diferenciación de $B$. abortus del resto de especies. En general los datos obtenidos y bibliográficos demuestran que la elección del oligonucleótido no afecta la sensibilidad de la prueba lo que concuerda con Leal - Klevezas et al. (1995a, 1995b y 2000); Queipo et al. (1997); Romero et al. (1995b) y Sreevatsan et al. (2000) quienes han utilizados esta técnica en muestra de sangre.

Dentro de las pruebas de serología, la Rosa de bengala mostró baja eficiencia respecto a la PCR. Esto se debe por un lado a la disminución de los niveles de anticuerpos observados en la prueba serológica. Y por otro lado a que los animales de donde se tomó las muestras hayan estado en la fase inicial de la enfermedad. Estos resultados concuerdan con los de Alton et al. (1976) y Colmero et al. (1996); quienes manifiestan que no se puede descartar la posibilidad de diagnosticar $B$. abortus en animales seronegativos y que, por las razones anteriormente comentadas, no fueran positivo en la inmunopruebas (RB). Y por otro lado los estudios realizados por Martínez et al. (1993); Martínez et al. (2000); Matar et al. (1996); Morata et al. (2001a, b); Queipo et al. (1997) y Sreevatsan et al. (2000), indican que el uso de la PCR en muestras de sangre ha sido más precisa en la detección de B. abortus, ya que es capaz de detectar ADN de organismos no viables y en la fase inicial de esta enfermedad, lo que concuerda con este trabajo. En la actualidad las pruebas serológicas son poco confiables cuando los animales se encuentran en la etapa inicial, pero que sin embargo son utilizadas en el campo.
En este trabajo se pudo comprobar las existencias de reacciones cruzadas y de muestras falsas positivas con algunos microorganismos aparentemente relacionados con Brucella, por analogía con los reportes demostrados en cuanto a la presencia de la molécula de perosomina en el LPS de algunas bacterias gramnegativas que afectan a muchos mamíferos. Estos resultados concuerdan con los reportados en otros estudios en donde el uso de PCR en muestras de sangre ha sido superior que la inmunoprueba en la detección de Brucella spp, Leal Klevezas et al. (1995a); Romero et al. (1995a, b).

Según reportes relacionados con PCR en otras especies domésticas se han obtenido buenos resultados; además esta técnica promete mucho para solucionar los problemas de esta enfermedad zoonótica por ser más sensible y específica que los métodos tradicionales. La técnica de PCR por su eficiencia nos reconfirma los resultados obtenidos con Rosa de bengala y en las campañas oficiales para erradicar la brucelosis.

\section{CONCLUSIONES}

Con base en los resultados obtenidos en el presente estudio se concluye que se pudo validar el protocolo de extracción de ADN. Además, se implementó la técnica de la PCR para el diagnóstico y confirmación de la Brucella abortus, en el Ecuador, demostrando que esta técnica fue más eficiente que la prueba Rosa de bengala, la sensibilidad y especificidad de la técnica de PCR está basado a los oligonucleótidos obtenidos de las secuencias 16S ARNr de Brucella abortus dándonos el resultado en seis horas.

\section{LITERATURA CITADA}

Al - Attas R.A; M. Al- Khalifa; Al - Q urashi A.R; Badawy M y N. Al - Gualy. 2000. Evaluation of PCR culture and serology for the diagnosis of acute human brucellosis. Ann. Saudi Med. 20 (3): $224-228$.

Alton, G; Jones, L; Angus, R. y Verger, I. 1976. Techniques for the Brucellosis. 30. Laboratory Imprimerie Louis Jean, París.

Bustamante S. J; Salazar H.F.I; Díaz A. E; Manzano C. C; Pérez G. R y Hernández A.L. 2000. Estudio bacteriológico y serológico de brucelosis en vacas revacunadas con dosis reducida de cepa S19 de Brucella abortus. Tec. Pecuaria Mex. 38(1): 35 42.

Cerba Internacional. 1998. Determinación analítica por la Reacción en cadena de la polimerasa Pág. 36. (Consultado noviembre 8/2006). Disponible en la página Web. http://www.cerba.com/docs/doc002.

Colmenero, J; Reguera, J; Martos, F. 1996. Complications associated with Brucella melitensis infection a study of 530 cases. Medicine.75:195-211 
Colmenero, J; Morata, P. 2001. Specificity of a Polymerase Chain Reaction Assay of a Target Sequence on the 31 - Kilodalton Brucella Antigen DNA Used to Diagnose Human Brucellosis. Journal of Clinical Microbiology.20: 127 - 131.

Dajer Abimerhi A. F; Gutierrez E. J y Zapatas D. 1998. Uso de las pruebas de ensayo inmunoabsorbente ligado a enzimas y aglutinación con rivanol para el diagnóstico de brucelosis bovina en Yucatán, Mérida. Vet. Mex. 29: $167-171$.

Instituto Colombiano Agropecuario (ICA). 1999. Informe sección de información y vigilancia, División de Sanidad animal, Sugerencia de fomento y servicios. ICA, Bogota, $118 \mathrm{p}$.

Leal-Klevezas, D; López-Merino, A; Martínez-Soriano, J. 1995a. Molecular detection of Brucella spp.: rapid identification of $B$. abortus biovar 1 using PCR. Arch. Med. Res. 26,263-267.

Leal-Klevezas, D; Martínez-Vásquez, I; López-Merino, A; Martínez-Soriano, J. 1995b. Single step PCR for the detection of Brucella spp. From blood and milk of infected animals. J. Clin. Microbiol. 33, 3087-3090.

Leal-Klevezas, D; Martínez-Vásquez, I; García-Cantu; López-Merino, A; Martínez-Soriano, J. 2000. Use of polymerase chain reaction to detect Brucella abortus biovar 1 in infected goats. Veterinary Microbiology 75, 91-97.

López - Merino A. R; Ortiz M; Pérez M. A; Magos C; Salvatierra B y Sepúlveda J. 1992. Seroepidemiología de la brucelosis en México. Salud Pública. Mex. 34: 210 - 230.

Martínez-Soríano, J; Cab-Barrera, E; Tamez-González, R; Leal-Klevezas, D. 1993. Detección de Brucella abortus por medio de la reacción en cadena de la polimerasa. Bioquímica. 18, 10-16.

Martínez, O; Vásquez, P; Montes, M; Morales-Loredo, A. 2000. Diagnóstico Simultáneo de brucelosis y tuberculosis mediante PCR múltiples. Vol.25 No. 2 Pág.53-57.

Matar, G; Khneisser, I; Abdelnoor, A. 1996. Rapid laboratory confirmation of human brucellosis by PCR analysis of a target sequence on the 31Kilodalton antigen DNA. J. Clin. Microbiol. 34, 477-478.

Mittal, K; Tizard; R. 1980.Studies on the relationship between Yersinia enterocolitica IX and Brucella abortus agglutinins in naturally infected animals .Res vet.Sci.28(3):311-314.

Morata, P; Queipo-Ortuño, I; Reguera, M; GarcíaOrdóñez, A; Pichardo Cristrina; Colmenero, D. 1999. Posttreatment Follow-Up of Brucellosis by PCR Assay. 37:12 4163-4166.

Morata, P; Queipo-Ortuño, I; Reguera, M; Miralles, F; López González, J; Colmenero, D. 2001a. Diagnostic Yield of a PCR Assay in Focal Complications of Brucellosis. 39:10 3743-3746.
Morata, P; Queipo-Ortuño, I; Colmenero, D. 2001 b. PCR Assay for Dignosis of Human Brucellosis. P.1654 - 1655.

Morata, P; Queipo-Ortuño, I; Reguera, M; Garcia Ordóñez, A; Cardenas, A; Colmenero, D. 2003. Developmet and Evaluation of a PCR - Enzyme - Linked Immunosorbent Assay for Diagnosis of Human Brucellosis.J. clin. Microbiol. 41: 144 148

Queipo-Ortuño, M; Morata, P; Ocon, P; Manchado, P; Colmenero, J. 1997. Rapid diagnosis of human brucellosis by peripheral-blood PCR assay, J. Clin. Microbiol. 35, 2927-2930.

Romero, C., Gamazo, C., Pardo M., López-Goñi. I., 1995a. Specific detecction of Brucella DNA by PCR. J. Clin. Microbiol. 33. 615-617.

Romero, C; Pardo, M; Grillo, J; Díaz, R; Blasco, M; López-Goñi, I. 1995b.- Evaluation of PCR and Indirect Enzyme-Linked Immunosorbent Assay on Milk Samples for Diagnosis of Brucellosis in Dairy Cattle. 33:12 3198-3200.

Romero, C; López -Goñi, I. 1999. Improved Method for purification of bacterial DNA from Bovine Milk for detection of Brucella spp. by PCR. A and Env. Microbiol. V65, No8, p.3735 - 3737.

SESA. 2002. Servicio Ecuatoriano de Sanidad Agropecuaria del Ecuador.

Sreevatsan, S; Bookout, B; Ringpis, F; Perumaalla, V; Ficht, A; Adams, G; Hagius, D; Elzer, H; Bricker, J; Kumar, K; Rajasekhar, M; Isloor, S; Barathur, R. 2000, A Multiplex Approach to Molecular Detection of Brucella abortus and/or Mycobacterium bovis Infection in Cattle. J. Clin. Microbiol. 38. 2602-2610.

Sutherland S. 1980. Immunology of bovine brucellosis. Vet. Bull., 50 (5), $359-369$ 